\title{
Differential Electrochemical Mass Spectrometry
}

\author{
Helmut Baltruschat \\ Institute for Physical and Theoretical Chemistry, University of Bonn, Bonn, Germany
}

Differential electrochemical mass spectrometry (DEMS) can be used not only to identify products or intermediates of continuous faradaic reactions, but also to characterize submonolayer amounts of adsorbates on polycrystalline and single crystal electrode surfaces by means of their desorption, because of its high sensitivity. One possibility to achieve this is to oxidize a carbonaceous species to $\mathrm{CO}_{2}$, which is quantitatively detected in the mass spectrometer. Many adsorbates can also be desorbed at certain potentials as such, or as the hydrogenated product, allowing a more direct characterization of the adsorbate. In some cases, a nonreactive desorption can be induced by displacement with a second adsorbate, yielding additional information. Interfacing an electrochemical cell to a mass spectrometer via a porous Teflon membrane can be achieved with a variety of cells. These will be described together with their specific advantages and characteristics. (J Am Soc Mass Spectrom 2004, 15, 1693-1706) (C) 2004 American Society for Mass Spectrometry

$\mathrm{T}$ The immediate detection of electrochemical reaction products shortly after their formation has long been a dream of former generations of electrochemists and is often still a difficult task. This is because, differently from homogeneous chemical kinetics, the amount of species formed at the electrode surface usually is comparatively small. Mass spectrometry was one of the first spectroscopic techniques, the potential of which was elucidated in this aspect. This was started by Bruckenstein and Gadde [1] who collected gaseous electrochemical reaction products in a vacuum system before detecting them by mass spectrometry (using electron impact ionization). Later, Wolter and Heitbaum [2, 3], still using a porous Teflon membrane covered by a $100 \mu \mathrm{m}$ lacquer of the electrocatalyst as the interface to the mass spectrometer, considerably improved the vacuum system so that the time constant became short enough to allow the on-line detection of volatile electrochemical reaction products, e.g., during cyclic voltammetry. Due to a proper design of the vacuum system including two pumping stages, product formation rates were measured; to distinguish the technique from product sampling, i.e., integrating approaches, the method was called "differential". Even at the beginning it was sensitive enough to detect desorption products corresponding to about one monolayer of adsorbed species at porous electrodes.

Published online October 26, 2004

Address reprint requests to Professor H. Baltruschat, Institute for Physical and Theoretical Chemistry, University of Bonn, Romerstrasse 164, D-53117 Bonn, Germany. E-mail: baltruschat@uni-bonn.de
Electrochemical reaction rates depend on the electrode potential applied. Cyclic voltammetry $(\mathrm{CV})$ is very popular for obtaining a fast, qualitative, and quantitative impression on the potential dependence of electrochemical reactions. Therefore in a typical DEMS experiment the ion current corresponding to given species of interest is recorded in parallel to the faradaic electrode current during the potential sweep, yielding the so-called mass spectrometric voltammograms, MSCV. Modern instruments allow the quasisimultaneous detection of up to 100 different ions. Other electrochemical techniques, such as potential step or galvanic step, have also been combined with DEMS.

In some respect, DEMS resembles the membrane introduction mass spectrometry (MIMS) [4]. This technique is used in analytical chemistry to detect trace amounts of nonpolar molecules in water; thin, nonporous membranes (silicon or Teflon) are used to separate these molecules from water. The nonporosity of the membranes has the advantage that much less water is reaching the vacuum; therefore, special pumping is not necessary. The drawback, however, is the relatively large response time of usually more than $10 \mathrm{~s}$.

In the last one or two decades the technique was developed much further. Rotating disc electrodes (RDE) connected to the vacuum system were developed allowing a defined convection and fast transport of the reaction species to the electrode surface [5]. It was shown that the sensitivity is high enough to use smooth and even single crystal electrodes in thin layer cells as the interface to a mass spectrometer [6]. The simultaneous use of a quartz crystal microbalance is possible 
[7] and, using a capillary as the inlet, DEMS can be used for high throughput testing of catalysts [8].

Electrocatalystic reactions, i.e., reactions in which the electrode surface is not only sink (or supplier) of electrons, but also acting as a heterogeneous catalyst, represent the largest field of application of the DEMS technique. Such mechanistic studies are often relayed to fuel cell research, but also to fundamental aspects which might be of practical relevance for environmentally important detoxification reactions, electrochemical gas sensors, or a better understanding of the reactions occurring with organic additives in galvanic plating baths. Purely fundamental reactions on single crystal electrode surfaces, including a determination of the surface coverage with a given species by electrodesorption and mass spectrometric detection, serve to build a link to similar studies in surface science (typically in UHV). Reactions at carbon supported nanoparticles were also studied $[9,10]$, as well as decomposition reactions in nonaqueous solvents $[11,12]$, and modifications of the technique allowed to study side products formed in batteries and fuel cells [13].

The lack of a commercial availability might be one reason that the technique is so far only used in research laboratories. On the other hand, following one of the setups described in literature, building the instrument should not be too difficult. The experimental setup might also be of interest for people working in heterogeneous catalysis in liquid phase.

To my knowledge, so far DEMS has not been used for purely analytical purposes, although the detection of volatile electrochemical degradation (oxidation/reduction) products might sometimes be superior to the direct detection. Compared with electrospray techniques, electron impact is more quantitative and thus the big advantage of DEMS is that semiquantitative values are obtained for reaction rates and surface coverage values.

An earlier review article on DEMS appeared in 1991 [14]. Emphasis was put on surface reactions in a review of 1999 [15]. This article will focus on the performance of the cells, the experimental setup and recent examples demonstrating the applicability of the technique.

\section{Cell Types}

In order to detect species which are produced at an electrode surface in solution by conventional mass spectrometry (i.e., using electron impact) they have to be transferred from the electrolyte phase to vacuum. The essential part for DEMS is, therefore, a membrane which separates the electrolyte from the vacuum, but which is permeable for volatiles. The second requirement is that the species are transferred from the electrode surface to this interface in a short period. Fortunately, for aqueous systems and also for some organic electrolytes, e.g. propylene carbonate [16] and some other solvents like the ionic liquids

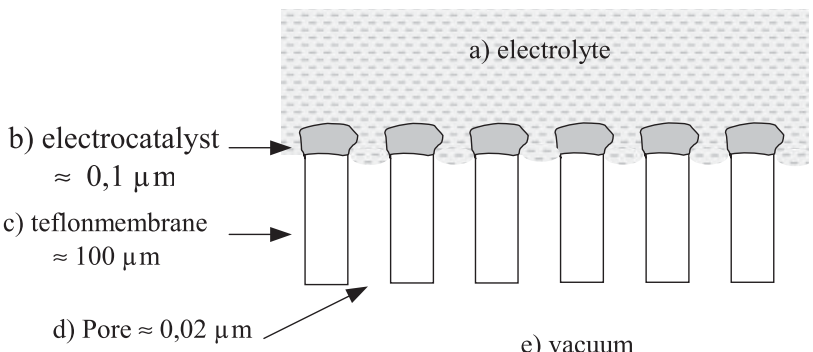

Figure 1. Schematic representation of a typical "sputtered" electrode (a) electrolyte, (b) catalyst sputter deposited, (c) Teflon, (d) pores in the membrane, (e) vacuum.

containing dimethylamine as constituent [17], the seperation of the electrolyte from the vacuum can be achieved by using porous Teflon membranes. Due to their hydrophobicity, the liquid does not penetrate through them, whereas dissolved gaseous and other volatile species readily evaporate in the pores.The critical pore size depends on the surface tension of the liquid and the contact angle between the liquid and Teflon. For water it is calculated to be $\mathrm{r}<0.8 \mu \mathrm{m}$ [2]. The Teflon membrane is usually supported by a glass or steel frit. A typical Teflon membrane (e.g., Gore-Tex) is $75 \mu \mathrm{m}$ thick and has a nominal pore width of $20 \mathrm{~nm}$ with a porosity of $50 \%$.

For a fast transfer of the species to the membrane, either the electrode has to be very close to the membrane, so that transport by diffusion is sufficiently fast, or additional convection has to be used. Several electrodes and cell types have been described:

\section{The Conventional Cell for DEMS}

In the classical approach, the electrocatalyst layer, e.g., $\mathrm{Pt}$, is sputter deposited onto the Teflon membrane. The resulting catalyst layer typically has a thickness of 50 to $80 \mathrm{~nm}$ and a roughness factor between 5 and 10 (a simple model of such an electrode is shown in Figure 1). Alternatively, as was done in the first DEMS experiments, a metallic lacquer (e.g., Doduco from Dürrwächter KG, Germany) containing small metallic particles can be painted onto the Teflon membrane. It has the advantage of a large roughness factor (50 to 100), permitting larger overall product formation. The disadvantage is the lower mechanical stability, and a much higher thickness (50 to $100 \mu \mathrm{m}$ ) leads to depletion of the electroactive species due to slow diffusion within the catalyst layer.

A typical cell for these electrodes, shown in Figure 2 , is optimized to have a small volume. This allows the use of expensive isotopically labeled compounds for mechanistic studies. The cell body may be made out of Teflon, the porosity of which sometimes leads to the absorbance of organic species, or preferably made of glass. The electrode is mechanically supported by a steel frit. The response time for an 


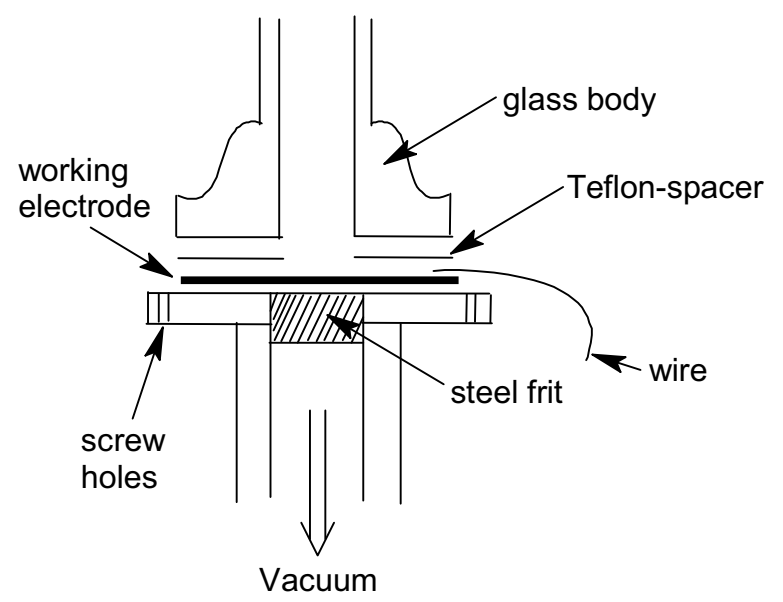

Figure 2. The conventional cell for DEMS.

electrochemical experiment was determined to be about $0.1 \mathrm{~s}$ [18], which is much larger than that of the vacuum system (see below), but still low enough for most electrochemical experiments.

A continuous forced convection may be achieved by simply introducing the electrolyte via a Teflon tube close to the electrode surface. When using volatile educts (such as the often studied CO), it must be kept in mind that because of evaporation, the concentration close to the surface of a sputtered electrode may be largely reduced, even when the electrochemical reaction is not diffusion-limited. The electrochemical reaction (and also the adsorption process) and evaporation are competing processes. Even reaction equilibria in solution might be shifted when they involve gaseous species, as observed during nitrate reduction [19]. In the case of the thicker lacquer electrodes, the thickness of the porous electrode may be comparable to the thickness of the Nernstian diffusion layer (if the evaporation is diffusion-limited) and the educt concentration may be different at the electrolyte side and at the Teflon membrane side of the porous electrode.

Product formation rates are monitored by recording the corresponding ion current: It will be shown below that the mass spectrometrically determined ion intensity $\mathrm{I}_{\mathrm{i}}$ is directly proportional to the incoming flow $\mathrm{J}_{\mathrm{i}}=$ $\mathrm{dn} / \mathrm{dt}$ in $\mathrm{mol} \mathrm{s}^{-1}$ of that species $\mathrm{i}$ and therefore

$$
\mathrm{I}_{\mathrm{i}}=\mathrm{K}^{\circ} \mathrm{J}_{\mathrm{i}}
$$

$\mathrm{K}^{\circ}$ contains all settings of the mass spectrometer and the ionization probability of the corresponding species. When the species is produced electrochemically, $J_{i}$ is given by the faradaic current $\mathrm{I}_{\mathrm{F}}$ corresponding to that process:

$$
\mathrm{J}_{\mathrm{i}}=\mathrm{N} \mathrm{I}_{\mathrm{F}} /(\mathrm{zF})
$$

where $\mathrm{z}$ is the number of electrons, $\mathrm{F}$ is the Faraday constant and $\mathrm{N}$ is the transfer efficiency, i.e., the ratio of the amount of the mass spectrometrically detected species to the total amount of species produced electrochemically. $\mathrm{N}$ may be less than 1 because a part of the produced species diffuses away from the electrode into the electrolyte. (When the current efficiency is not equal to $100 \%, \mathrm{I}_{\mathrm{F}}$ has to be replaced by its product with the current efficiency.) Therefore:

$$
\mathrm{I}_{\mathrm{i}}=\left(\mathrm{K}^{*} / \mathrm{z}\right) \mathrm{I}_{\mathrm{F}} \text {, with } \mathrm{K}^{*}=\mathrm{K}^{\circ} \mathrm{N} / \mathrm{F}
$$

Calibration is possible when using a known electrochemical reaction, such as hydrogen evolution. From eq $3, \mathrm{~K}^{*}$ and $\mathrm{N} \cdot \mathrm{K}^{\circ}$ are obtained straight away. Often the oxidation of adsorbed $\mathrm{CO}$ on Pt-electrodes during an anodic potential sweep is used to calibrate the mass spectrometer for $\mathrm{CO}_{2}$. The integrated faradaic oxidation current and the integrated ion current for $\mathrm{CO}_{2}$ can also be used. In this case double layer charging effects, which amount to $20 \%$ of the oxidation charge even after background substraction, have to be taken into account. The origin is mainly the different double layer charge at a given potential with and without adsorbed $\mathrm{CO}$ $[3,20,21]$.

\section{Rotating Electrode Inlet}

In classical electrochemistry, rotating disc electrodes are often used because of enhanced and well defined mass transport. In some cases it may be interesting to use a rotating porous electrode as inlet system to the mass spectrometer as it was described in reference [5].

Using such a rotating inlet system, the transfer efficiency $\mathrm{N}$ was determined under defined diffusion conditions from a plot of the diffusion limited faradaic currents for hydrogen evolution versus the corresponding values of $I_{i}$ for different rotation speeds.

According to Fick's laws of diffusion, the ratio of the flux to the membrane to the flux into the bulk of the electrolyte, and therefore $\mathrm{N}$, is given by the corresponding concentration gradients, which are inversely proportional to the Nernstian diffusion layer thickness. For the approximately $100 \mathrm{~nm}$ thin, sputtered platinum electrodes, a transfer efficiency above 0.9 was obtained even at high rotation speeds. In the whole range of rotation speeds, the concentration gradient across the thin catalyst layer is much larger than the concentration gradient away from the electrode into the bulk electrolyte, with a correspondingly large Nernstian diffusion layer. However, using lacquer electrodes 50 to $100 \mu \mathrm{m}$ thick, the transfer efficiency approached only 0.7 at low rotation speeds and was 0.3 at high rotation speeds [5]. Here, the diffusion layer from the macroscopic surface of the electrode to the Teflon membrane is comparable to the diffusion layer in the bulk electrolyte.

The situation is somewhat different when the transfer efficiency for the desorption products of an adsorbate layer is considered: For the case of a fully covered 


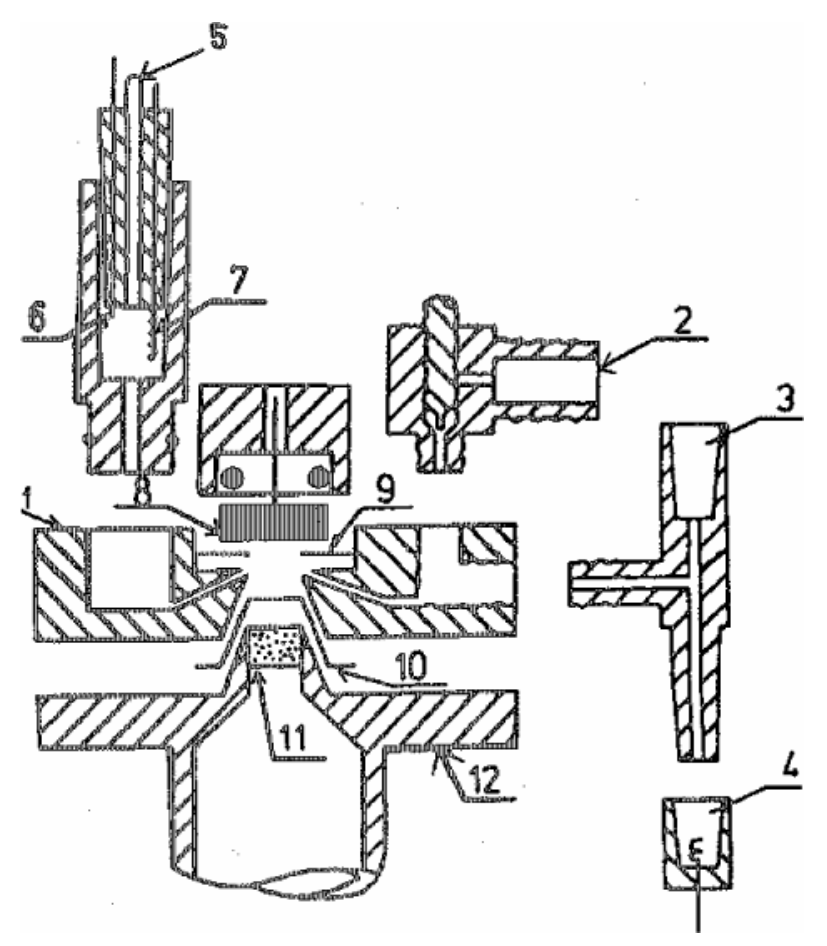

Figure 3. Thin layer cell (1) cell body made from titanium, (2) connection to electrolyte supply, (3) T-connection, (4) counter electrode, (5) electrolyte outlet, (6) capillary to reference electrode, (7) second counter electrode, (8) single crystal electrode, (9) Teflon spacer, 50-100 $\mu \mathrm{m}$ thickness; inner diameter $6 \mathrm{~mm}$, (10) microporous Teflon foil, interface between electrochemical cell and vacuum, (11) steel frit, (12) stainless steel support.

electrode, the product is formed evenly distributed within the catalyst layer, including the pores (and not only formed at the macroscopic surface). Therefore, for carbon dioxide formation from adsorbed $\mathrm{CO}$ on Pt-transfer efficiencies slightly above 0.5 were found for the lacquer electrode even at high rotation speeds, whereas the transfer efficiency for the sputtered electrode still was around 0.9.

\section{A Cell Allowing the Use of Massive Electrodes: The Thin Layer Cell}

In order to be able to use massive electrodes for DEMS, e.g., single crystal electrodes, the thin layer cell of Figure 3 was developed [22, 23]. The massive electrode with a diameter of $1 \mathrm{~cm}$ is separated from the porous hydrophobic Teflon membrane by a 50 to $100 \mu \mathrm{m}$ thick electrolyte layer. Volatile species produced at the electrode surface diffuse to the Teflon membrane within $2 \mathrm{~s}$. The Teflon membrane is mechanically supported by a steel frit. The distance between electrode and Teflon membrane is ascertained by a spacer (or two to achieve a doubled distance, i.d. $6 \mathrm{~mm}$, o.d. $12 \mathrm{~mm}$ ) made from the same Teflon membrane. Due to compression of this soft spacer, the distance is less than the nominal thickness.
The cell body is made of passivated titanium because of its mechanical stability and inertness. (The passivating procedure has to be repeated from time to time.) Two capillaries positioned at opposite sides serve as electrolyte inlet and outlet and as a connection to the reference and counter electrode. Due to the large IR drop in the thin layer of electrolyte, it is advantageous to use two counter electrodes, in the outlet and inlet. By connecting both counter electrodes to the potentiostat via different resistors, it is ascertained that the current through the capillary to the reference electrode is less than half of the total current.

This cell can be used for both desorption experiments under stopped flow conditions as well as for the measurements of product formation rates during faradaic reactions under continuous flow. In the first case, nearly all of the desorption product can diffuse within $2 \mathrm{~s}$ to the Teflon membrane, where it evaporates. (Experimentally, we obtained transfer efficiencies $\mathrm{N}$ in the range of 0.9 to 0.95 [24]) During a continuous flow of electrolyte, however, a considerable part of the product is transported out of the thin layer volume and lost, because a part of the product is formed close to the outlet of the cell and has no chance to reach the Teflon membrane. Experimentally, transfer efficiencies of 0.2 and below for practical flow rates of $1 \mu \mathrm{l} / \mathrm{s}$ and above were found [25].

A modification of a thin layer cell is described in [26]. A cell allowing the study of electrodes under illumination is possible with the cell shown in Figure 4 [27]. Here, volatile products have to diffuse sideways through a Teflon spacer and therefore the response time is fairly large.

\section{The Dual Thin Layer Cell for Continuous Flow Through of Electrolyte}

For faradaic reactions, which have to be performed under a continuous flow of electrolyte on account of the rapid depletion of the reactant in the thin layer cell, is the "dual thin layer cell" shown in Figure 5 is better suited. Here, the complete cell consists of two separate compartments for electrochemistry and mass spectrometric detection. The electrolyte first enters the thin layer compartment in front of the electrode ("wall-jet" geometry) and then flows through one of four (or six) capillaries into the lower compartment ("detection cell"), where volatile products can reach the Teflon membrane. This cell offers the additional advantage that it can be combined with a quartz crystal microbalance; then, one of the electrodes of the quartz is also used as a working electrode for DEMS [7].

To test the applicability of DEMS for various substances, an aqueous solution of test analytes was delivered to the cell and the mass spectrometric ion current was recorded as a function of the flow rate $u$ $=\mathrm{dV} / \mathrm{dt}$ and, after calibration of the mass spectrom- 

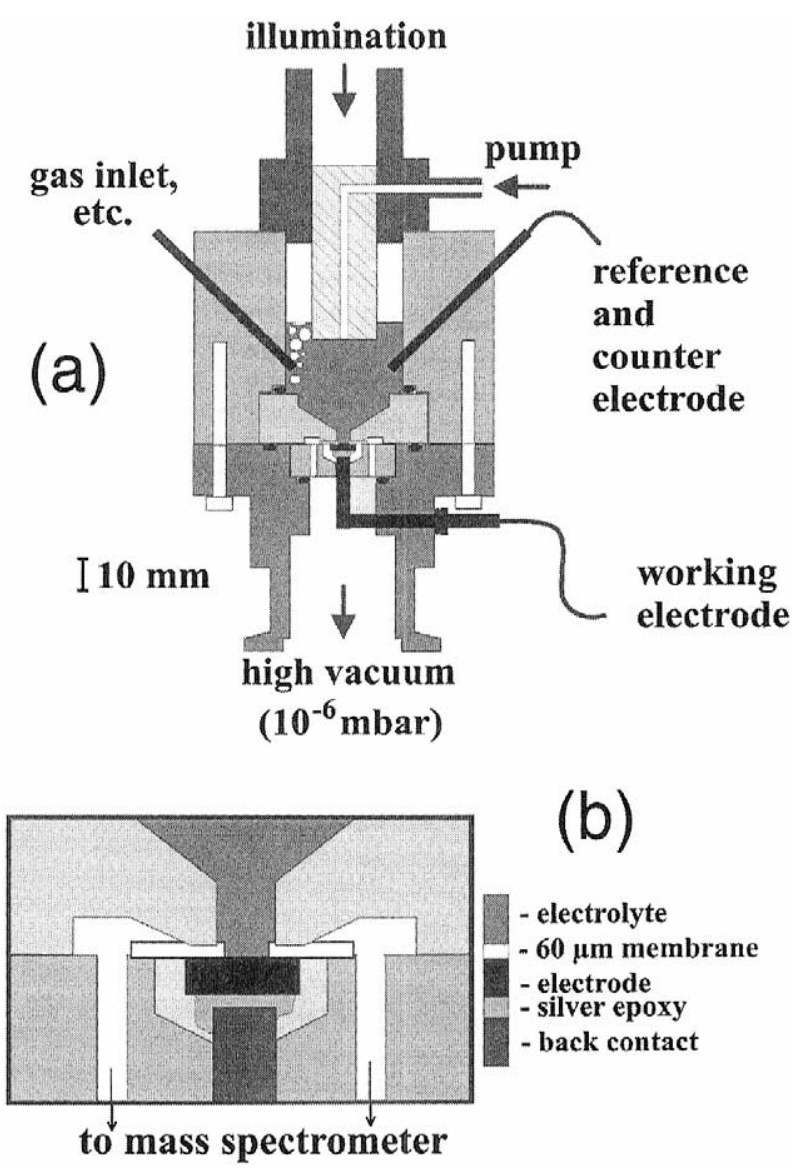

Figure 4. A DEMS cell for using massive electrodes under illumination (from reference [27]).

eter, converted to flux $\mathrm{J}_{\mathrm{i}}$ through the membrane (Figure 6; the working electrode was replaced by a glass dummy.) The straight line corresponds to the assumption of complete turnover of the incoming species where $\mathrm{J}_{\mathrm{i}}=\mathrm{K}^{\circ} \mathrm{c}_{\mathrm{i}} \mathrm{u}$ ( $\mathrm{c}_{\mathrm{i}}$ : concentration of species i). As expected, sensitivity as given by the ratio J/c is highest for gases and lowest for hydrophilic substances. Obviously, the transfer of soluble species is not diffusion-limited. Under identical conditions, benzene was detected even at concentrations of $1 \mu \mathrm{M}$, demonstrating the high sensitivity of the technique.

In electrochemical thin layer flow cells, the faradaic current is proportional to $u^{x}$ with $x=1 / 3$ for diffusion limited processes, as long as the flow rate $u=d V / d t$ is not so small that most of the incoming species react at the electrode surface. In the latter case, $\mathrm{I}_{\mathrm{F}}$ is proportional to the amount of species entering the cell and therefore to $\mathrm{u}^{1}$. The same proportionality should hold for the ion current. However, a logarithmic plot of the data gives a value of 0.6 for $x$ in the case of $\mathrm{CO}_{2}$ and also Ar, which might reflect a certain similiarity of the cell to "wall-jet" cells, for which $x=3 / 4$.

The collection efficiency $f_{1}$ is the ratio of reacting species [given by $\mathrm{I}_{\mathrm{F}} /(\mathrm{z} F)$ ] to the amount of species entering the cell-compartment:

$$
\mathrm{f}_{1}=\mathrm{I}_{\mathrm{F}} /(\mathrm{zF} \cdot \mathrm{c} \cdot \mathrm{u})
$$

Similarly, the collection efficiency $\mathrm{f}_{2}$ for the mass spectrometric part of the cell is given by

$$
\mathrm{f}_{2}=\mathrm{I}_{\mathrm{i}} /\left(\mathrm{K}^{\circ} \cdot \mathrm{c}_{\mathrm{i}} \cdot \mathrm{u}\right)
$$

This value can be obtained from Figure 6 by forming the ratio between the experimental value and the value given by the straight line. In an electrochemical experiment, the average concentration of the product in the fluid leaving the electrochemical part of the cell is given by

$$
\mathrm{c}_{\mathrm{i}}=\mathrm{I}_{\mathrm{F}} /(\mathrm{zF} \cdot \mathrm{u})
$$

Assuming complete mixing, the collection efficiency $\mathrm{f}_{2}$ of the "detection" cell is identical to the transfer efficiency $\mathrm{N}$ as defined in eq 2 and therefore:

$$
\mathrm{I}_{\mathrm{i}}=\mathrm{f}_{2} \mathrm{~K}^{\circ} \mathrm{I}_{\mathrm{F}} /(\mathrm{zF})=\mathrm{NK}^{\circ} \mathrm{I}_{\mathrm{F}} /(\mathrm{zF})
$$

However, complete mixing is not achieved in general. A numerical simulation of the concentration in the thin layer cell, depicted in Figure 7, clearly shows that a complete mixing is only achieved at low flow rates of up to 1 and $2 \mu \mathrm{L} / \mathrm{s}$ [28]. For $\mathrm{CO}_{2}$, typical experimental values for $\mathrm{f}_{2}$ and $\mathrm{N}$ are: $\mathrm{N}=\mathrm{f}_{2}=0,9$ at $1 \mu \mathrm{L} / \mathrm{s}$ and $\mathrm{N}=0,6 ; \mathrm{f}_{2}=0,37$ at $10 \mu \mathrm{L} / \mathrm{s}$. (here, $\mathrm{f}_{2}$ was determined from the ion current observed when a saturated $\mathrm{CO}_{2}$ solution was introduced, $\mathrm{N}$ was obtained from oxidizing adsorbed $\mathrm{CO}$.) Exact values for both $\mathrm{N}$ and $\mathrm{f}_{2}$ not only depend on the diffusion coefficient of the species, but also on the geometry of the cell, in particular its thickness, which, due to the flexibility of the spacer and the force exerted thereupon, may vary from experiment to experiment. This has severe consequences for the calibration of the experimental setup: If, and only if $\mathrm{N}=\mathrm{f}_{2}$, a calibration is achieved by introducing a solution with a known concentration into the cell.

Sometimes a nonvolatible product may be converted to a volatible one in a homogeneous reaction with different solution. An example is the reaction of carbonate formed in alkaline solution with an acidic solution to form $\mathrm{CO}_{2}$. This is possible with a modification of the dual thin layer cell involving an additional mixing stage.

\section{The Pinhole Inlet}

A simple approach, also allowing the use of massive electrodes was described in [29]. Here, the gas inlet is a pinhole, several micrometers in diameter, located at the hemispherical end of a glass tube, $4 \mathrm{~mm}$ in diameter, which is covered by a Teflon film of $50 \mu \mathrm{m}$. Electrodes can be used in the hanging meniscus arrangement. A further advantage is the small overall amount of substance entering the vacuum system via the pinhole. 


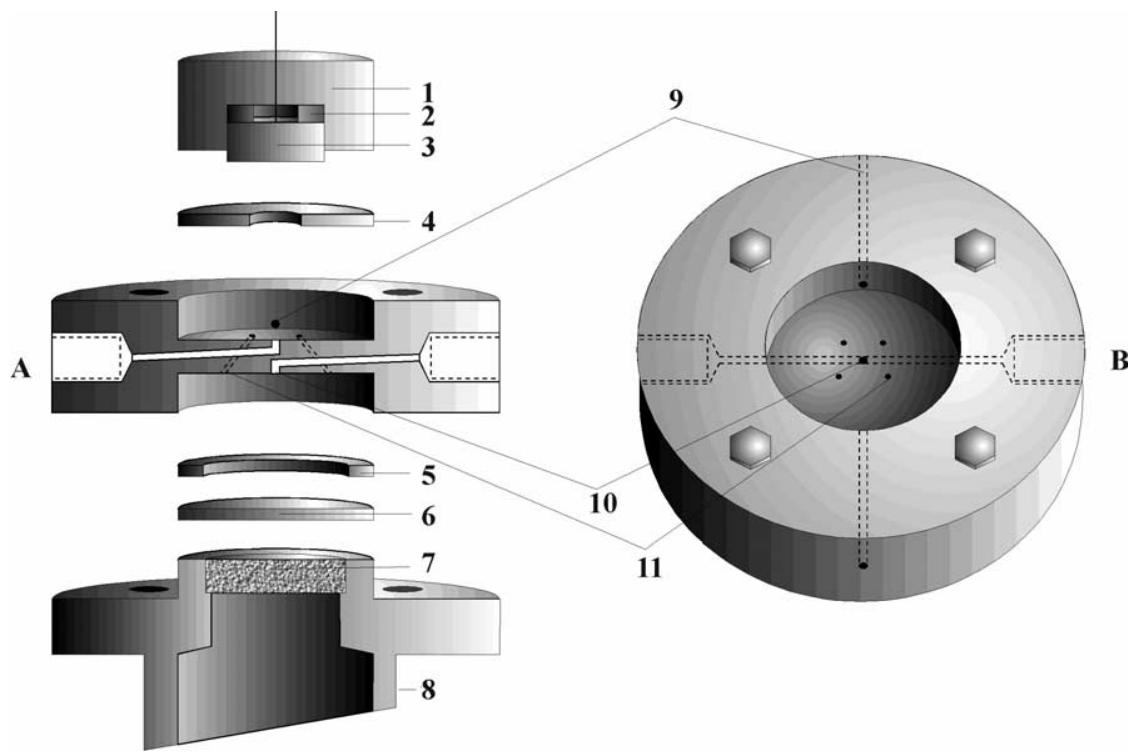

Figure 5. Dual thin layer cell from experiments under constant flow through (Kel F) (1) Kel-F support; (2) Kalrez; (3) single crystal; (4), (5) Teflon spacer; (6) porous Teflon membrane; (7) stainless steel frit; (8) stainless steel connection to MS; (9) capillaries for flushing with Ar; (10) inlet-oulet capillaries; (11) connecting capillaries. (a) Side view of Kel-F body of the cell; (b) top view of the cell.

However, a disadvantage seems to be that the volatile products are sampled, not only from a small cylindrical volume between the pinhole and the electrode surface in front of the pinhole, but from a larger volume. The superposition of the products' planar diffusion away from the surface and the spherical diffusion to the pinhole leads to a complicated time dependence and larger response times. A largely improved version of this approach is described in [30].

\section{Scanning DEMS}

A very interesting further development was recently described by Jambunathan and Hillier [8, 31]. They used a PTFE tubing with an i.d. $0.15 \mathrm{~mm}$, covered by a Goretex membrane. This capillary probe is scanned 100 $\mu \mathrm{m}$ above a surface of a multielectrode system, thus allowing a lateral resolution in the low $\mathrm{mm}$ range. The overall time constant of this approach is approximately $10 \mathrm{~s}$, but certainly will be lowered in the future.

\section{The Vacuum System}

Despite the hydrophobicity of the Teflon membrane, an appreciable amount of electrolyte evaporates. Since the flow is molecular within the pores for the total gas flow (mainly water vapor) a value of $\mathrm{J}^{\prime}=0.09 \mathrm{mbar} 1 \mathrm{~s}^{-1}$ $\mathrm{cm}^{-2}$ is calculated [2] for a porosity of 0.5 and a vapour pressure for water of 23 mbar at $20^{\circ} \mathrm{C}$, which corresponds to $0.25 \mathrm{ml}$ of water per h. An upper value for the expected vapour pressure lies around $100 \mathrm{mbar}$ (water

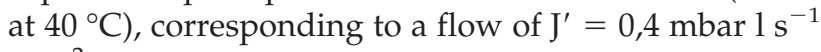
$\mathrm{cm}^{-2}$.
Under stationary conditions, this amount has to be pumped by the pumping system:

$$
J^{\prime}=\mathrm{p} \cdot \mathrm{S}
$$

With an upper limit for the pressure $\mathrm{p}$ of $10^{-3}$ mbar in the ion source and a pumping speed $S$ of $2001 \mathrm{~s}^{-1}$, a flow of 0.2 mbar $1 \mathrm{~s}^{-1}$ is allowed and therefore an electrode area of $0.5 \mathrm{~cm}^{2}$ is acceptable.

The time constant $\tau$ for the detection of a species is given directly by the ratio of the ionization chamber volume $\mathrm{V}_{0}$ (total volume of the chamber in which the

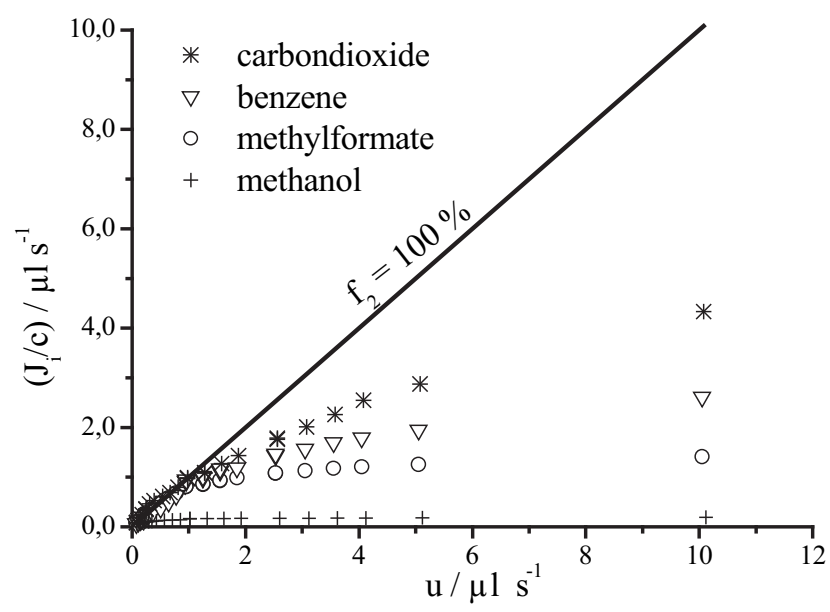

Figure 6. Performance of the dual thin layer cell: ion currents converted to flux and normalized by the concentration $\left(\mathrm{CO}_{2}: 38\right.$ $\mathrm{mM}$, benzene: $23 \mathrm{mM}$, formic acid methylester: $2 \mathrm{mM}$, methanol: $2 \mathrm{mM})$. 


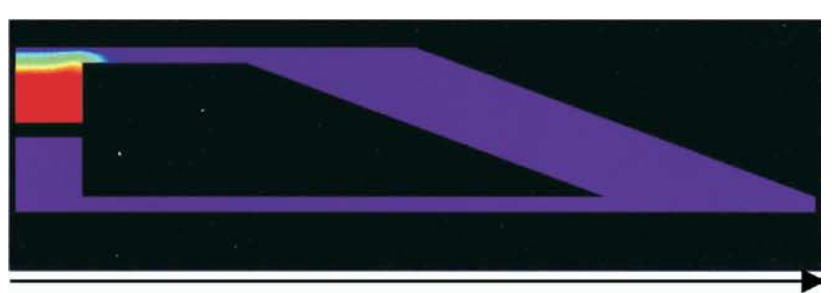

$\mathrm{u}=0.04 \mu \mathrm{L} / \mathrm{s} \quad 2: \mathrm{Re}=0.1$

r

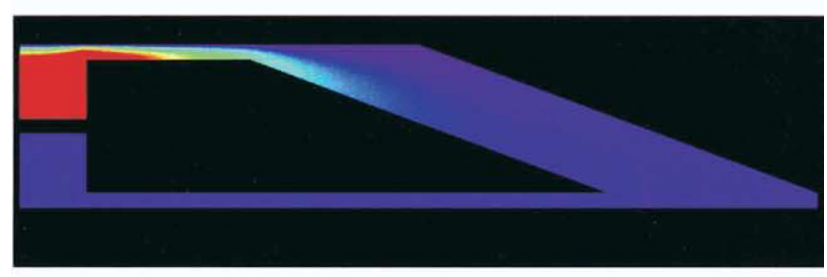

$\mathrm{u}=0.2 \mu \mathrm{L} / \mathrm{s} \quad 3: \operatorname{Re}=0.5$

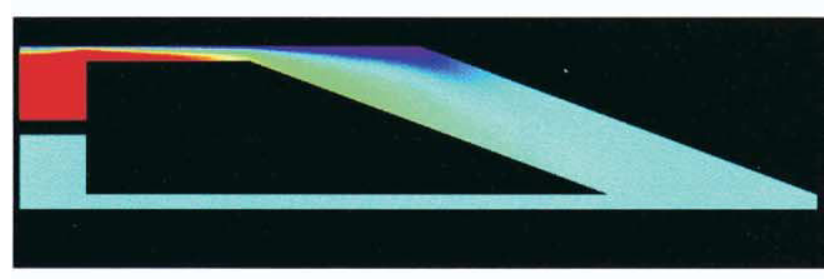

$\mathrm{u}=0.4 \mu \mathrm{L} / \mathrm{s} \quad 4: \operatorname{Re}=1$

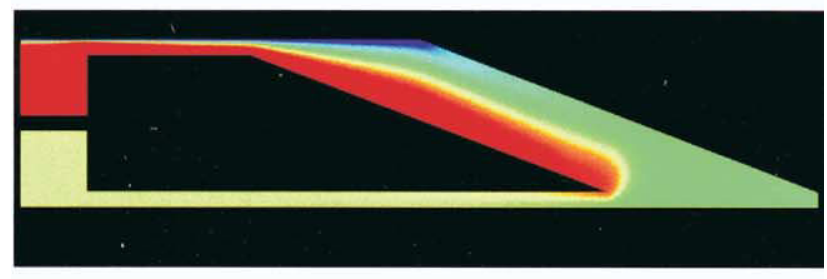

$\mathrm{u}=2 \mu \mathrm{L} / \mathrm{s} \quad 5: \operatorname{Re}=5$

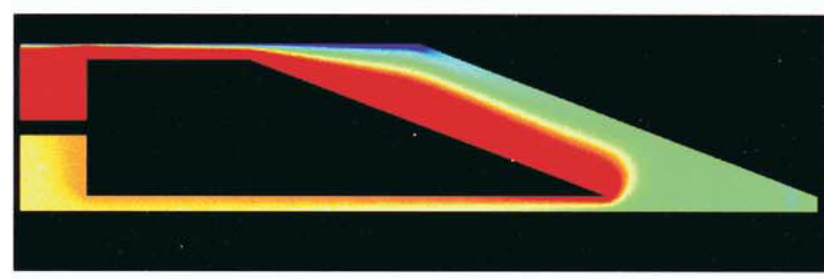

$\mathrm{u}=3.6 \mu \mathrm{L} / \mathrm{s} \quad 6: \operatorname{Re}=9$

Figure 7. Numerical simulation of the concentration profile in the dual thin layer cell of Figure 4 for a diffusion limited process at the electrode. Shown is a section of the cell of Figure 5 starting at the center (left) and ending at one of the capillaries. (However, in the simulation, a cylindrical symmetry had to be assumed instead of single capillaries; therefore, this simulation serves for visualization and does not exactly represent the concentrations.) No process (nor any evaporation) is assumed to occur at the membrane. Red: high educt concentration, product concentration zero; blue: zero educt concentration, maximum product concentration. (Re is Reynolds number corresponding to the flow rate indicated; $r$ is the distance from the center of the cell.) ion source is situated; first pumping stage) to the pumping speed, as seen in the following: under nonstationary conditions, the change of pressure (e.g., after a sudden change of $\mathrm{J}^{\prime}$ ) is given by:

$$
\mathrm{V}_{0} d p / d t=\mathrm{J}^{\prime}-\mathrm{p} \cdot \mathrm{S}
$$

with the solution:

$$
\mathrm{p}=\left(\mathrm{J}^{\prime} / \mathrm{S}\right) *\left(1-\mathrm{e}^{-\mathrm{t} / \tau}\right), \text { where } \tau=\mathrm{V}_{0} / \mathrm{S}
$$

With a pumping speed of $200 \mathrm{l} / \mathrm{s}$ and a volume $\mathrm{V}_{0}$ of 11 , a time constant of $5 \mathrm{~ms}$ is thus obtained, which is much less than the time constant attainable with the electrochemical cells.

The analyzer section, of course, has to be pumped separately to achieve a pressure below $10^{-5}$ mbar. A 50 $1 / \mathrm{s}$ turbomolecular pump is sufficient. Figure 8 shows our experimental setup. The electrochemical cell is connected to the first vacuum chamber via a valve at Position 3. Another valve at Position 4 leads to the calibration volume (see below). A shutter between ionization chamber and the analyzer section allows the difference in pressure.

The effort of pumping can be largely reduced by allowing a much higher pressure in the chamber of the first pumping stage of e.g., $10^{-2}$ mbar and by simply pumping with a rotational pump at an accordingly lower pumping speed [32]. A sufficiently low time constant can easily be achieved by reducing its volume. In that case, the ion source has to be placed in a separate chamber which is pumped together with the analyzer of the mass spectrometer by a simple turbo molecular pump of $50 \mathrm{l} / \mathrm{s}$. A commercial gas inlet system can be used. The disadvantage of such a system is that condensation or multilayer adsorption of the species might occur in that pressure range, cf. the vapor pressure of naphthalene, which is only $0.1 \mathrm{mbar}$ at room temperature; heating of the gas inlet system may thus be necessary.

The mass spectrometrically determined ion intensity $I_{i}$ is directly proportional to the partial pressure $p_{i}$ of that species $\mathrm{i}$ and therefore to the incoming flow $\mathrm{J}_{\mathrm{i}}=$ $\mathrm{dn} / \mathrm{dt}=\mathrm{J}_{\mathrm{i}}{ }^{\prime} / \mathrm{RT}$ :

$$
\mathrm{I}_{\mathrm{i}}=\mathrm{ap}_{\mathrm{i}}=\mathrm{aJ}_{\mathrm{i}}{ }^{\prime} / \mathrm{S}=\mathrm{RTJ}_{\mathrm{i}} \mathrm{a} / \mathrm{S}=\mathrm{K}^{\mathrm{o}} \mathrm{J}_{\mathrm{i}}
$$

where " $a$ " is a proportionality constant containing the settings of the mass spectrometer and the ionization probability of the corresponding species.

Experimentally, both the low time constant of the vacuum setup of several ms as well as the proportionality of $I_{i}$ with the faradaic current were verified $[2,3]$.

Calibration of the mass spectrometer is achieved by connecting a separate calibration volume $V_{c}$ to the first vacuum chamber via a calibration leak (e.g., a leak valve). The inflow rate $\mathrm{J}_{\mathrm{i}}{ }^{\prime}$ is then given by the pressure decrease in the calibration volume $\mathrm{dp}_{\mathrm{c}} / \mathrm{dt}$ :

$$
\mathrm{J}_{\mathrm{i}}{ }^{\prime}=\mathrm{V}_{\mathrm{c}} \mathrm{dp} \mathrm{p}_{\mathrm{c}} / \mathrm{dt}
$$




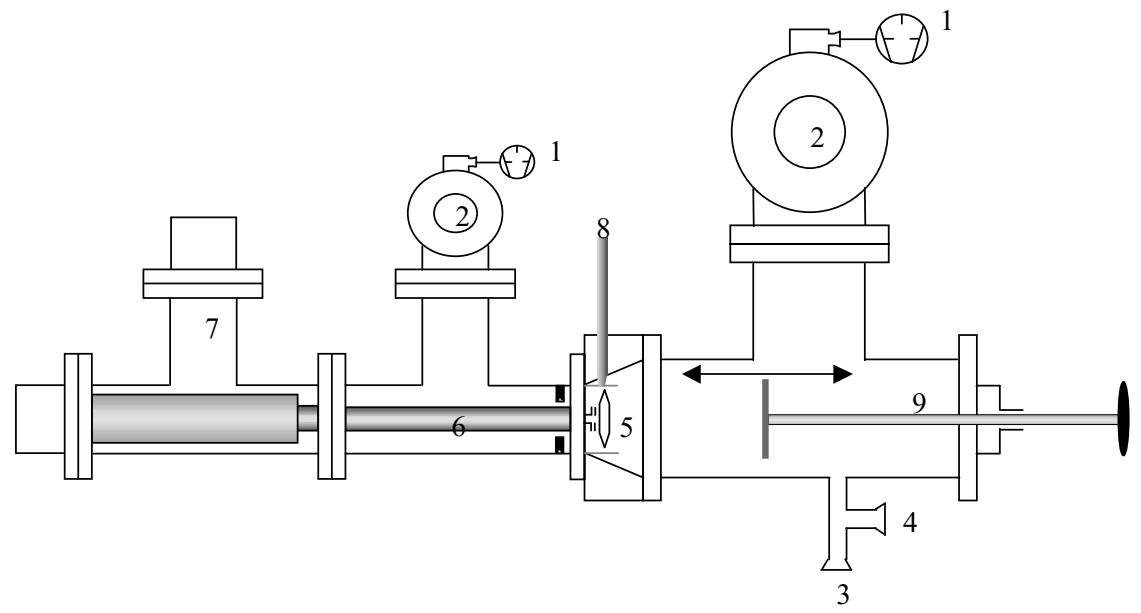

Figure 8. The vacuum system (1) rotary pumps, (2) turbomolecular pumps, (3) connection to the electrochemical cell, (4) connection to the calibration leak, (5) ion source, (6) quadrupol rods, (7) secondary electron multiplier, (8) direct inlet, (9) linear drive.

$\mathrm{I}_{\mathrm{i}}=\mathrm{K}^{\circ} \mathrm{J}_{\mathrm{i}}=\mathrm{K}^{\circ} \mathrm{J}_{\mathrm{i}}{ }^{\prime} / \mathrm{RT}=\left(\mathrm{K}^{\circ} / \mathrm{RT}\right) \mathrm{V}_{\mathrm{c}} \mathrm{dp} \mathrm{p}_{\mathrm{c}} / \mathrm{dt}$

$\mathrm{K}^{\circ}$ can thus be calculated from the pressure decrease in the calibration volume, i.e., from a plot of the ion current $I_{i}$ versus the differentiated pressure $p_{c}$.

This calibration procedure can be used not only for gases (most commonly $\mathrm{CO}_{2}$ ), but also for volatile liquids. Special care, however, has to be taken that no adsorption or absorption occurs in a part of the calibration setup. Due to the limited linear range and a possible interference of the partial pressure of $\mathrm{H}_{2} \mathrm{O}$ on the sensitivity, the same conditions as during the measurement should exist during calibration of the instrument. In particular, this means that during calibration the electrochemical cell is connected to the vacuum system.

\section{Factors Influencing the Detectability of a Species}

The sensitivity with respect to a given species-as given by $\mathrm{K}^{*}$ or $\mathrm{K}^{\circ}$ as defined above-is not only dependent on the ionization probability, the fragmentation, and the transmission of the mass spectrometer, but largely on the amount of species entering the MS, which determines the partial pressure in the ion chamber. The rate of evaporation (the mass transport through the capillaries) is largely determined by the vapor pressure of the species over the corresponding liquid and thus by the Henry constant:

$$
\frac{d n}{d t}=k_{p} p_{i}^{\text {surface }} \text { with } p_{i}^{\text {surface }}=K_{H} \cdot c
$$

$k_{p}$ is the rate constant for the transport through the capillaries of the membrane, assuming that at the vacuum side the pressure is negligible.

With a pore diameter of $20 \mathrm{~nm}$ and a pore length of
$150 \mu \mathrm{m}$ (thickness of the membrane), $k_{p}=8 \cdot 10^{-8} \mathrm{~mol}$ mbar $^{-1} \mathrm{~s}^{-1}$ is obtained, which compares reasonably with the experimental value found for ethanol and methanol of $4 \cdot 10^{-8}$ mol $\mathrm{mbar}^{-1} \mathrm{~s}^{-1}$ [33].

For species with a limited solubility such as gases or unpolar molecules the partial pressure for a saturated solution is identical to 1 bar (gases) or the vapor pressure of the pure liquid $\left(\mathrm{p}_{0}\right)$. Assuming Henry's law to hold over the whole range of solubility, the vapor pressure is thus given by

$$
p_{i}=K_{H} \cdot c=\frac{p_{0}}{c_{\text {sat }}} \cdot c
$$

As indicated by the flow rate dependence in Figure 6, for species which have a high vapor pressure above the solution, their diffusion to the liquid-gas interface is rate determining. This consideration holds when diffusion is well defined as in the flow through cell.

\section{Oxidation of Small Organic Molecules- Fuel Cell Related Studies}

From the very beginning, one of the main applications of DEMS was the elucidation of the oxidation mechanisms of species which could serve as possible fuels in fuel cells. For example, in an experiment involving the sequential adsorption of $\mathrm{H}^{13} \mathrm{COOH}$, subsequent rinsing with supporting electrolyte followed by an electrolyte exchange with $\mathrm{H}^{12} \mathrm{COOH}$ containing electrolyte, it was shown that the adsorbate formed from $\mathrm{HCOOH}$ on a $\mathrm{Pt}$ electrode does not take part in the continuous faradaic oxidation at low potentials [20]. Thus, the so-called parallel path mechanism, postulated in literature long before, could be proven.

Also in the case of methanol oxidation, a parallel reaction path had already been suggested by Bagotzky et al. in 1977 [34] on the basis of a strange dependence 


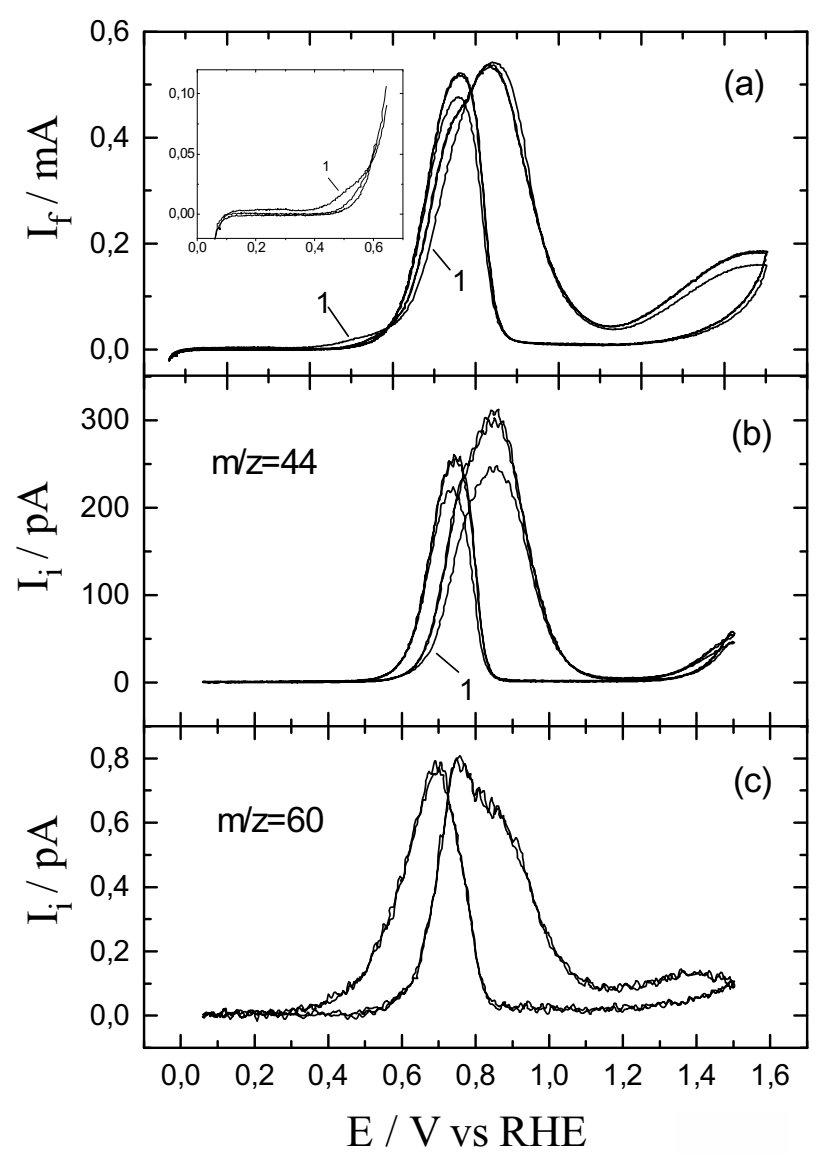

Figure 9. Simultaneously recorded cyclic voltammogram (CV) (a), mass spectrometric CV (MSCV) for $m / z=44(\mathbf{b})$, and MSCV for $m / z=60$ (c) on smooth polycrystalline Pt in $0.1 \mathrm{M}$ methanol + $0.5 \mathrm{M} \mathrm{HClO}_{4}$ solution. Scan rate: $10 \mathrm{mV} \mathrm{s}^{-1}$, electrolyte flow rate: $5 \mu \mathrm{L} \mathrm{s}^{-1}$. Three cycles are shown, "1" indicates the first cycle. Inset: expanded view of the faradaic current at low potentials.

of the oxidation current on the convection of the electrolyte. Its recent proof is a nice demonstration for the use of the dual thin layer flow through cell.

A cyclic voltammogram is recorded for the oxidation of methanol at $\mathrm{Pt}$ at constant flow rate. Simultaneously the ion currents for $\mathrm{m} / \mathrm{z}=44$ and $\mathrm{m} / \mathrm{z}=60$ are recorded (Figure 9). The ion current for $m / z=60$, which corresponds to methylformate, indicates the formation of formic acid (reacting with methanol to the ester) as an intermediate of the oxidation reaction. The shape of the ion current curves follows that of the faradaic current. It can also be seen that the formation of methylformate starts at lower potentials than that of $\mathrm{CO}_{2}$. Better suited for a quantitative evaluation are experiments, in which the potential is stepped from $0.1 \mathrm{~V}$, where no reaction is occurring, to a given value, where the oxidation occurs at a constant potential (cf. Figure 10). The decrease of the ion currents with time is due to the increasing coverage of the surface by adsorbed CO ("self poisoning"). The reaction order can be evaluated separately for the faradaic current and the formation rate for $\mathrm{CO}_{2}$. The experimental values for smooth $\mathrm{Pt}$ are 0.4 and 0.14 , respectively [35].
Therefore, the rate determining step (rds) for the formation of $\mathrm{CO}_{2}$ and for the formation of intermediates are not the same. Either the rds is not the first charge transfer step (different from what is commonly believed), or the soluble products such as $\mathrm{HCOOH}$ are formed not as intermediate of the reaction to $\mathrm{CO}_{2}$, but in a parallel reaction.

More directly, the existence of a parallel reaction mechanism is shown by the flow rate dependence of the current efficiency. The current efficiency A is that part of the faradaic current which is used for the formation of $\mathrm{CO}_{2}$ (cf. eq 3) and therefore is a qualitative measure for the amount of dissolved intermediates, which leave the electrochemical compartment of the whole cell without being further oxidized.

$$
A=\frac{I_{i} / K^{*}}{I_{F} / z}
$$

Since at low flow rate the probability for an intermediate to reach the electrode surface and react further is higher than at high flow rates, the current efficiency should depend on the flow rate used. Experiments in which the oxidation occurred at constant potential after a potential step show that the current efficiency is considerably lower than $100 \%$, but independent of the flow rate ( for a $0.1 \mathrm{M}$ methanol solution at $0.6 \mathrm{~V}$ between 16 and $18 \%$ for flow rates between 1 and $30 \mu \mathrm{L}$

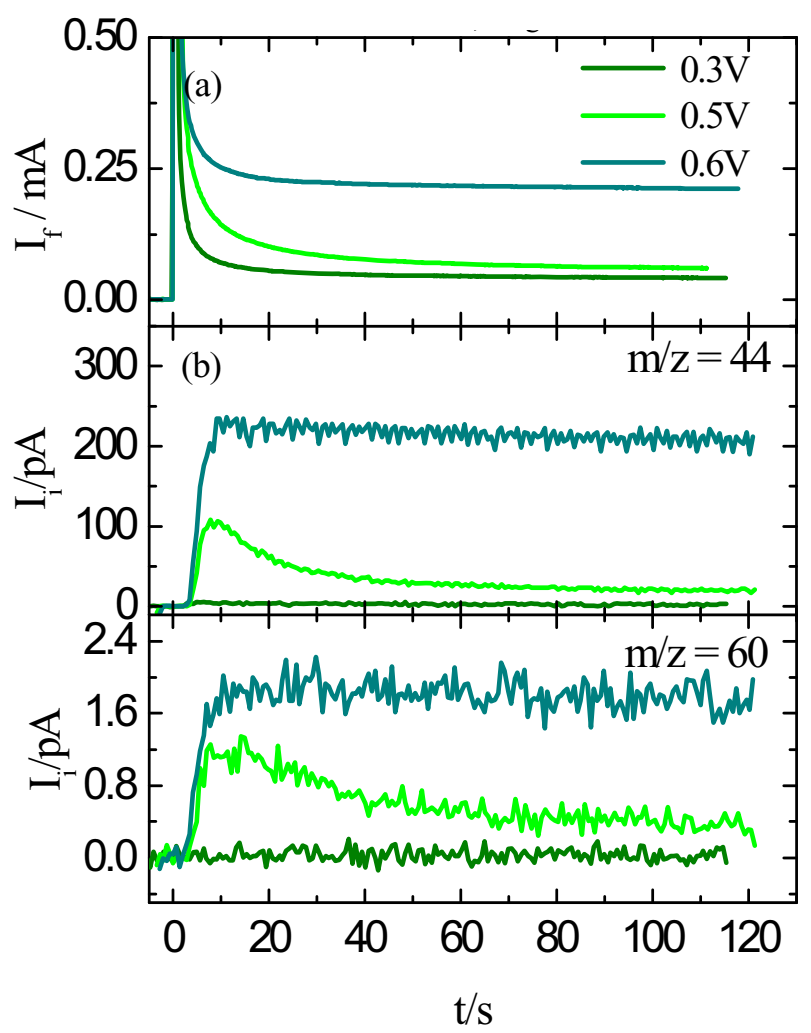

Figure 10. Transients of faradaic current (a) and ion current (b) on Pt nanoparticles on activated carbon (XC72) deposited on GC (loading, $10 \mu \mathrm{g} / \mathrm{cm}^{2}$ ). $0.1 \mathrm{M}$ methanol + $0.5 \mathrm{M} \mathrm{H}_{2} \mathrm{SO}_{4}$. 


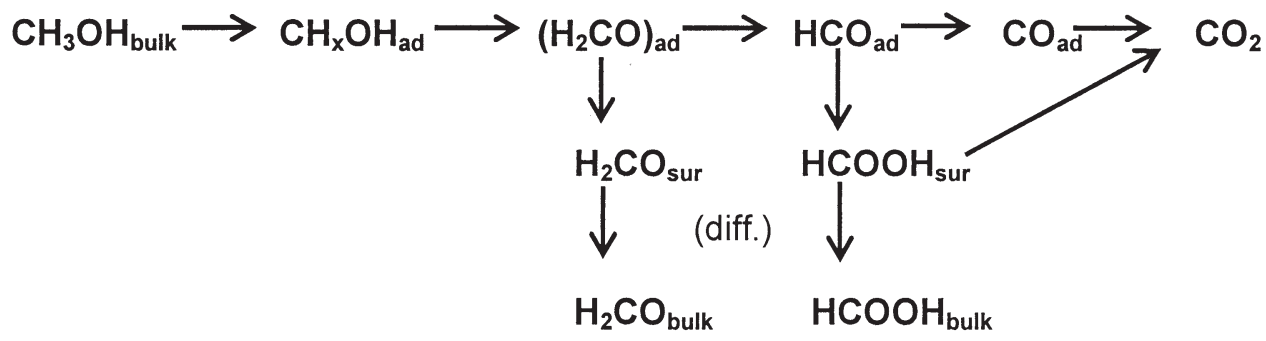

Scheme 1

$\mathrm{s}^{-1}$ ). The only possibility to explain this is to assume a parallel oxidation path leading directly to $\mathrm{CO}_{2}$ and another one leading to adsorbed intermediates [36].

Diffusion away from the electrode (and transport out of the cell) is faster than the reaction to $\mathrm{CO}_{2}$. This is visualized in Scheme $\mathbf{1}$.

Of course, in the absence of any convection the intermediates will also react to $\mathrm{CO}_{2}$. This reaction is, under the chosen flow rates, slower than the diffusion and transport away from the electrode.

When, instead of using a smooth electrode, a $26 \mu \mathrm{m}$ thick $\left(0.4 \mathrm{mg} \mathrm{cm}^{-2} \mathrm{Pt}\right)$ catalyst layer is used in order to simulate the membrane electrode assembly in a PEM fuel cell, the current efficiency approaches $100 \%$ because diffusion of the intermediates out of the catalyst layer is slow and the species have a high chance to react further to $\mathrm{CO}_{2}$. When, on the other hand, such a catalyst layer is thin and the total $\mathrm{Pt}$ loading is small (such as in the experiment of Figure 9), the efficiency is close to that found for polycrystalline Pt. This effect has also been studied more systematically [9].

Under flow through conditions at a Pt electrode, we found that the amount of methylformate is approximately $10 \%$ of the amount of $\mathrm{CO}_{2}$ formed (which itself under those conditions only contributes $20 \%$ to the total current). A quantitative determination of the amounts of formaldehyde and formic acid is difficult because they are not volatile enough. However, a detailed knowledge of the products and, in particular, of their dependence on catalyst structure and composition would be helpful in improving fuel cell catalysts. An indirect determination of formic acid and formaldehyde, however, is possible from a determination of the amount of methanol consumed, which, due to mass conservation, is equal to the total of all produced species [36]. A second equation for the determination of the unknown amounts (or formation rates) of formic acid and formaldehyde is the sum of the oxidation currents leading to the three products, which is identical to the experimental faradaic current in the potential step experiment (the amount of methylformate is negligible in this context). The difficulty in this approach is the exact determination of the methanol consumption, which is small in relation to its total concentration in the electrolyte. Therefore other approaches have been used.

Using high methanol concentrations of $1 \mathrm{M}$, Hillier and coworkers assume that the formic acid is com- pletely converted to methylformate and identify the amount of methylformate detected with the amount of formic acid formed [8]. Mass and charge balance as described above then yield the amount of formaldehyde produced. However in their approach using a Teflon tubing as inlet, mass transfer and convection are not well defined, and intermediates may be oxidized further to $\mathrm{CO}_{2}$. Jusys and Behm also used the methylformate signal to calculate the amounts of formic acid and formaldehyde produced in the dual thin layer flow through cell, assuming that $10 \%$ of formic acid is converted to methylformate [9].

\section{Hydrogen Evolution During Formaldehyde Oxidation}

Probably one of the most puzzling electrochemical reactions, which is also of great technological importance in electroless metal deposition, is the hydrogen evolution during formaldehyde oxidation at $\mathrm{Ib}$ metal electrodes and at potentials very positive of the reversible hydrogen evolution potential. It has been known for a long time that this reaction proceeds via the overall equation

$$
\begin{aligned}
2 \mathrm{HCHO}+4 \mathrm{OH}^{-} \rightarrow & 2 \mathrm{HCOO}^{-}+2 \mathrm{H}_{2} \mathrm{O} \\
& +\mathrm{H}_{2}+2 \mathrm{e}^{-} .
\end{aligned}
$$

Using DEMS, this has been verified by Vaskelis and Jusys, who have also studied the kinetic isotope effect and who, by using isotopic isomers, verified that the evolved hydrogen solely originates from the formaldehyde molecule and not from water [37-40]. When using a mixture of HCHO and DCDO, not only $\mathrm{H}_{2}$ and $\mathrm{D}_{2}$ but also $\mathrm{HD}$ are formed; therefore, both atoms in the hydrogen molecule originate from separate formaldehyde molecules, which is only possible if hydrogen atoms are adsorbed on these electrodes [41]. It is clear that $\mathrm{H}_{2}$ molecules are not oxidized at positive potentials at $\mathrm{Ib}$ metals because their dissociation is not possible on these surfaces. It is, however, astonishing that adsorbed $\mathrm{H}$-atoms are not oxidized either, but desorbed as $\mathrm{H}_{2}$.

Hydrogen from formaldehyde can also be transferred to other molecules via its adsorbed state at $\mathrm{Ib}$ metals in a heterogeneous, potential dependent 


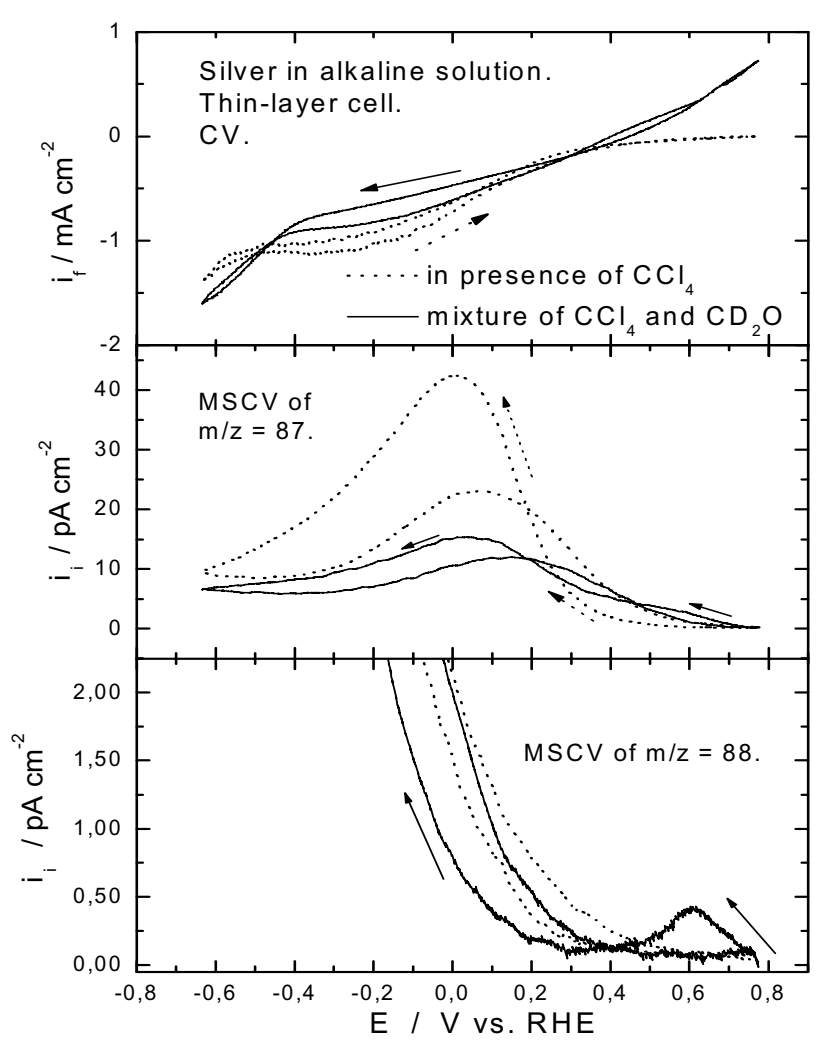

Figure 11. Hydrogen transfer from formaldehyde to $\mathrm{CCl}_{4}$, top: cyclic voltammogram at $\mathrm{Ag}\left(0.1 \mathrm{M} \mathrm{KOH}, 0.5 \mathrm{M} \mathrm{K}_{2} \mathrm{SO}_{4}\right)$ in the dual thin layer cell; $10 \mathrm{mV} / \mathrm{s} ; 3 \mu \mathrm{L} / \mathrm{s}$; middle: ion current for $\mathrm{m} / \mathrm{z}=87$ $\left(\mathrm{CHCl}_{3}\right)$; bottom: ion current for $\mathrm{m} / z=88\left(\mathrm{CH}_{2} \mathrm{Cl}_{2}\right.$ and $\left.\mathrm{CDCl}_{3}\right)$; broken line: saturated by $\mathrm{CCl}_{4}$ only; straight line $0.001 \mathrm{M} \mathrm{CD}_{2} \mathrm{O}$ plus $\mathrm{CCl}_{4}$ ).

chemical reaction. In Figure 11, top, the cyclic voltammogram for the reduction of $\mathrm{CCl}_{4}$ with and without added deuterated formaldehyde is shown. Cathodic currents are attributable to $\mathrm{CCl}_{4}$ reduction (and reduction of formaldehyde to methanol), positive currents due to formaldehyde oxidation which is paralleled by formation of $\mathrm{H}_{2}$ (not shown). In the middle, the potential-dependent formation rate of $\mathrm{CCl}_{4}$ is shown, which is decreased in the presence of formaldehyde due to its competitive reduction. The bottom mass spectrometric cyclic voltammogram shows the formation of $\mathrm{CH}_{2} \mathrm{Cl}_{2}$. Only in the presence of deuterated formaldehyde a peak at $0.6 \mathrm{~V}$ is visible, which originates from $\mathrm{CDCl}_{3}$ and shows that the hydrogen atom originates from formaldehyde. Similar results have been obtained at a $\mathrm{Cu}$ electrode (when using $\mathrm{HCHO}$, this peak due to transfer of $\mathrm{H}$ is visible in the MSCV for $m / z=87$ ).

\section{Characterization of Organic Adsorbates}

DEMS has been proven useful for studying the surface structure dependence of hydrogenation and oxidation reactions of such simple molecules as ethane and benzene. Also, the temperature dependent formation of adsorption states could be elucidated [42].
For the demonstration of the suitability of DEMS for the characterization of larger adsorbates, two examples shall be presented. The first involves biphenyl at a single crystalline $\mathrm{Pt}(111)$ electrode (Figure 12) [43]. Biphenyl is adsorbed at $0.4 \mathrm{~V}$ from a saturated solution containing $0.5 \mathrm{M} \mathrm{H}_{2} \mathrm{SO}_{4}$ as supporting electrolyte. After its exchange with the pure supporting electrolyte, the potential is swept to negative potentials. Desorption of biphenyl starts around $0 \mathrm{~V}$, as shown by the increase of the ion current for $m / z=154$, which is its molecular ion. The further increase of the ion current in the anodic sweep and its very slow decrease is in part due to a slow desorption process and in part due to the very low solubility $\left(5 \times 10^{-5} \mathrm{M}\right)$, which limits the concentration gradient and thus leads to slow diffusion from the electrode to the Teflon membrane. Only a small part of the adsorbate is hydrogentated to cyclohexylbenzene, probably at defect sites of the $\operatorname{Pt}(111)$ surface. The current in the anodic sweep and subsequent sweeps in the hydrogen adsorption region $(0.1$ to $0.3 \mathrm{~V})$ is close to that at the bare $\operatorname{Pt}(111)$ for hydrogen adsorption (broken

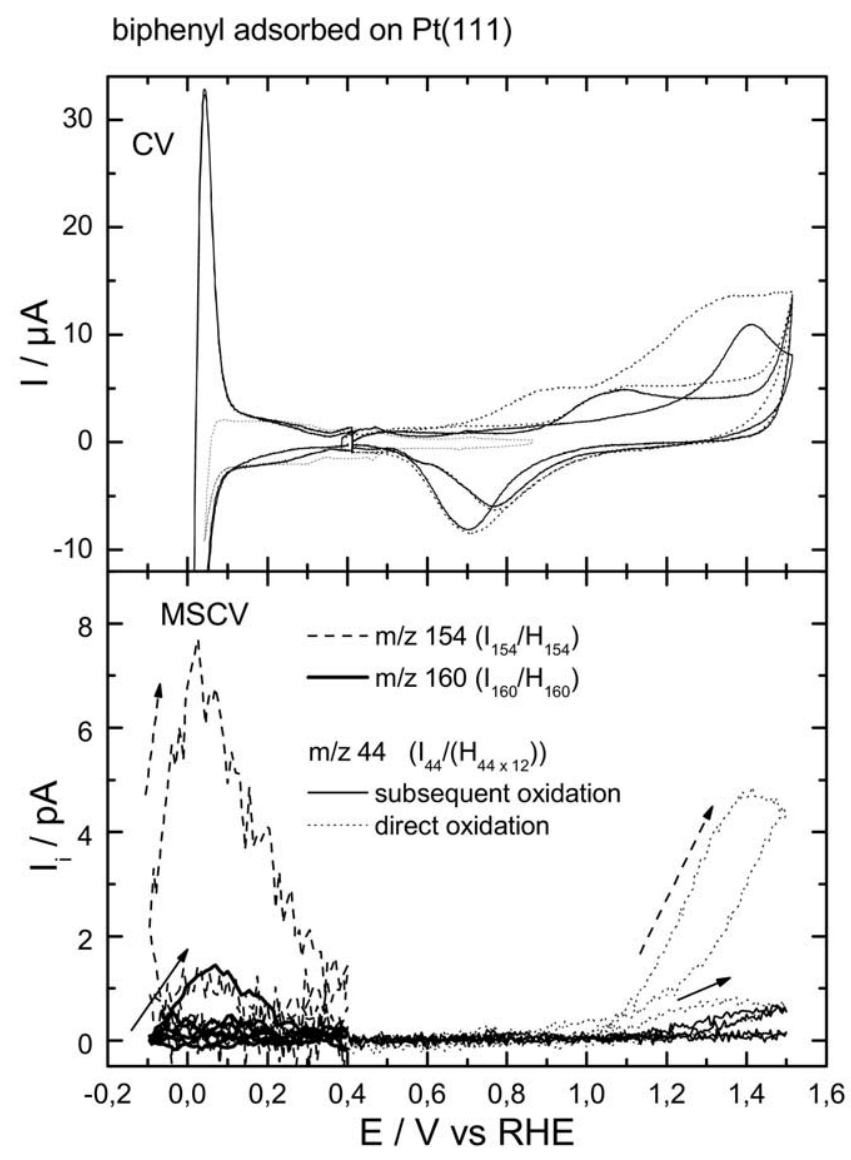

Figure 12. Desorption of preadsorbed biphenyl on $\mathrm{Pt}(111)$; Ead $=0,4 \mathrm{~V} ; \mathrm{v}=10 \mathrm{mV} / \mathrm{s} ; 0,5 \mathrm{M} \mathrm{H}_{2} \mathrm{SO}_{4}, \mathrm{~A}_{\mathrm{w}}=0,3 \mathrm{~cm}^{2}$; top: broken line: $\mathrm{CV}$ of $\mathrm{Pt}(111)$ in supporting electrolyte; straight line: cathodic desorption with subsequent oxidation; dotted line: direct oxidation; bottom: broken line: $m / z=154$ biphenyl; straight line (thick): $m / z=160$ cyclohexylbenzene; straight line (thin): $\mathrm{m} / \mathrm{z}=44 \mathrm{CO}_{2}$; subsequent oxidation of remaining adsorbate, dotted line: $\mathrm{m} / \mathrm{z}=$ $44 \mathrm{CO}_{2}$, direct oxidation. 


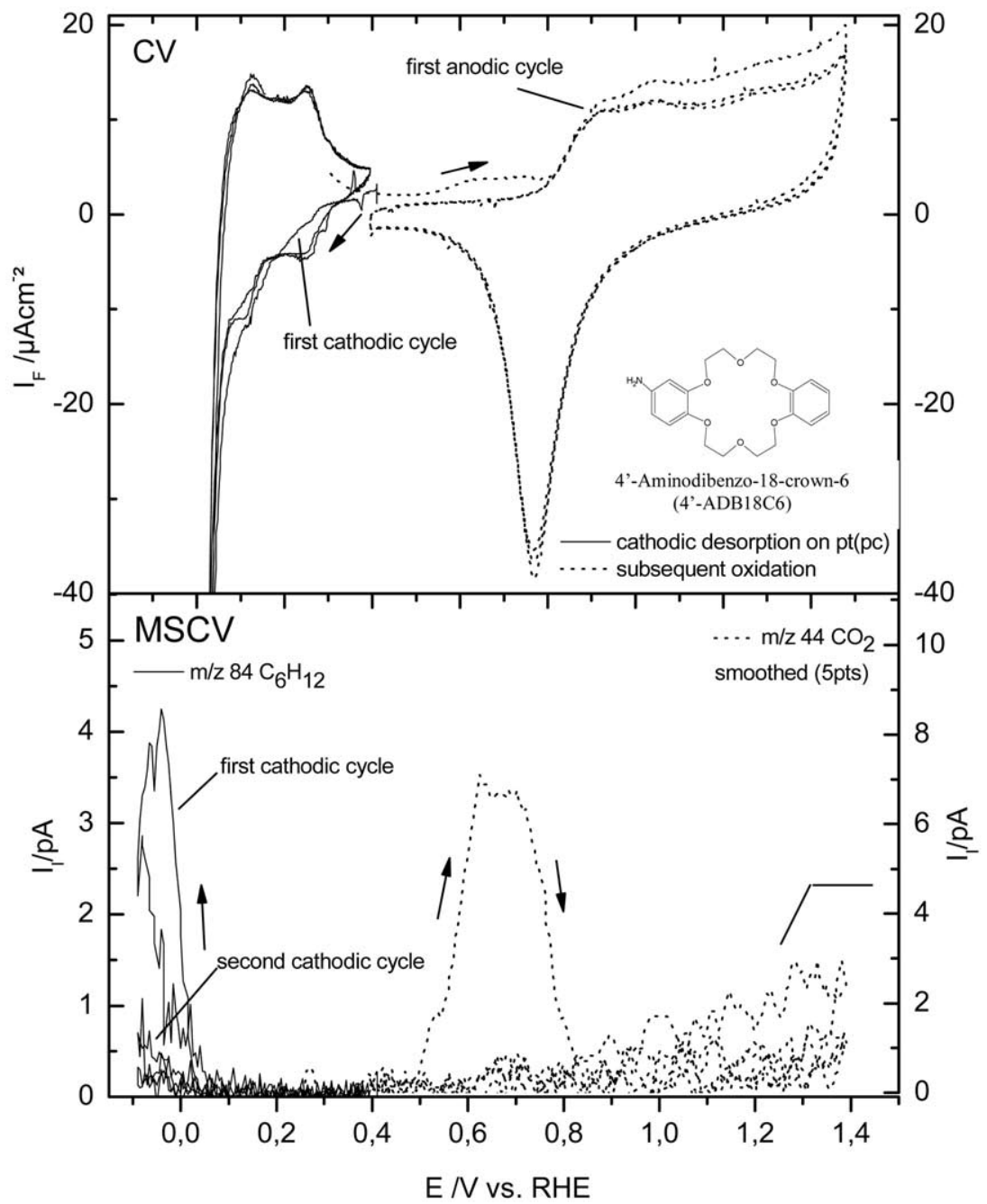

Figure 13. Cathodic desorption and subsequent oxidation of $4^{\prime} \mathrm{A}-\mathrm{DB}-18 \mathrm{C} 6$ on $\mathrm{Pt}(\mathrm{pc})$. (a) $\mathrm{CV} 10$ $\mathrm{mV} / \mathrm{s}$, black line: cathodic cycles down to $-0.1 \mathrm{~V}$; green line: subsequent anodic cycles $(0.4 \mathrm{~V}-1.5 \mathrm{~V})$; (b) MSCV of mass 84 for desorbing cyclohexane and mass 44 for oxidation of remaining adsorbate.

line), demonstrating that desorption is complete. No signal was observed for benzene or cyclohexene, therefore bond breaking between the two aromatic systems does not occur. Only a small amount of the adsorbate stays on the surface and is oxidized to $\mathrm{CO}_{2}$ in a sweep to $1.15 \mathrm{~V}$.

Differently from the case of adsorbed benzene or other simple molecules, where after calibration of the system the surface coverage can be calculated from the integrated ion current of the desorbing species, a calibration for biphenyl is difficult because of its low vapor pressure. However, after calibration for $\mathrm{CO}_{2}$, the amount of adsorbed biphenyl can be quantified through oxidation of the adsorbate to $\mathrm{CO}_{2}$ in a direct sweep in anodic direction from the integrated ion current for $\mathrm{CO}_{2}$, assuming that oxidation is complete and $\mathrm{CO}_{2}$ is the only oxidation product. The value of $0.2 \mathrm{nmol} \mathrm{cm}{ }^{-2}$ is somewhat smaller than that of benzene $(0.3 \mathrm{nmol}$ $\mathrm{cm}^{-2}$ ), as expected. Note that no $\mathrm{CO}_{2}$ is evolved during a first oxidation wave between 0.8 and $1 \mathrm{~V}$. This is also similar to the case of benzene on $\operatorname{Pt}(111)$ and was ascribed to the formation of a partially oxidized, adsorbed intermediarte, possibly a quinone species.

On polycrystalline $\mathrm{Pt}$, the total coverage is the same, but hydrogenation during the sweeps to negative potentials is much more dominant: half of the adsorbate desorbs as cyclohexylbenzene, one fourth as bicyclohexyl, and another fourth without hydrogenation.

Much effort is currently being undertaken in functionalizing surfaces, e.g., in the context of molecular electronics. For anchoring more complicated molecules onto Au surfaces, thiol groups are mostly used. As an alternative, we are exploiting the use of unsaturated functions for fixing molecules at Pt. A key issue is their stability as function of the potential. Crown ethers with attached benzene rings are first model compounds [44]. As before with biphenyl, 4'-amino-dibenzo-18-crown-6 is adsorbed at polycrystalline Pt at $0.4 \mathrm{~V}$. After electrolyte exchange and upon a sweep in negative direction, cyclohexane is formed (Figure 13). In a subsequent 


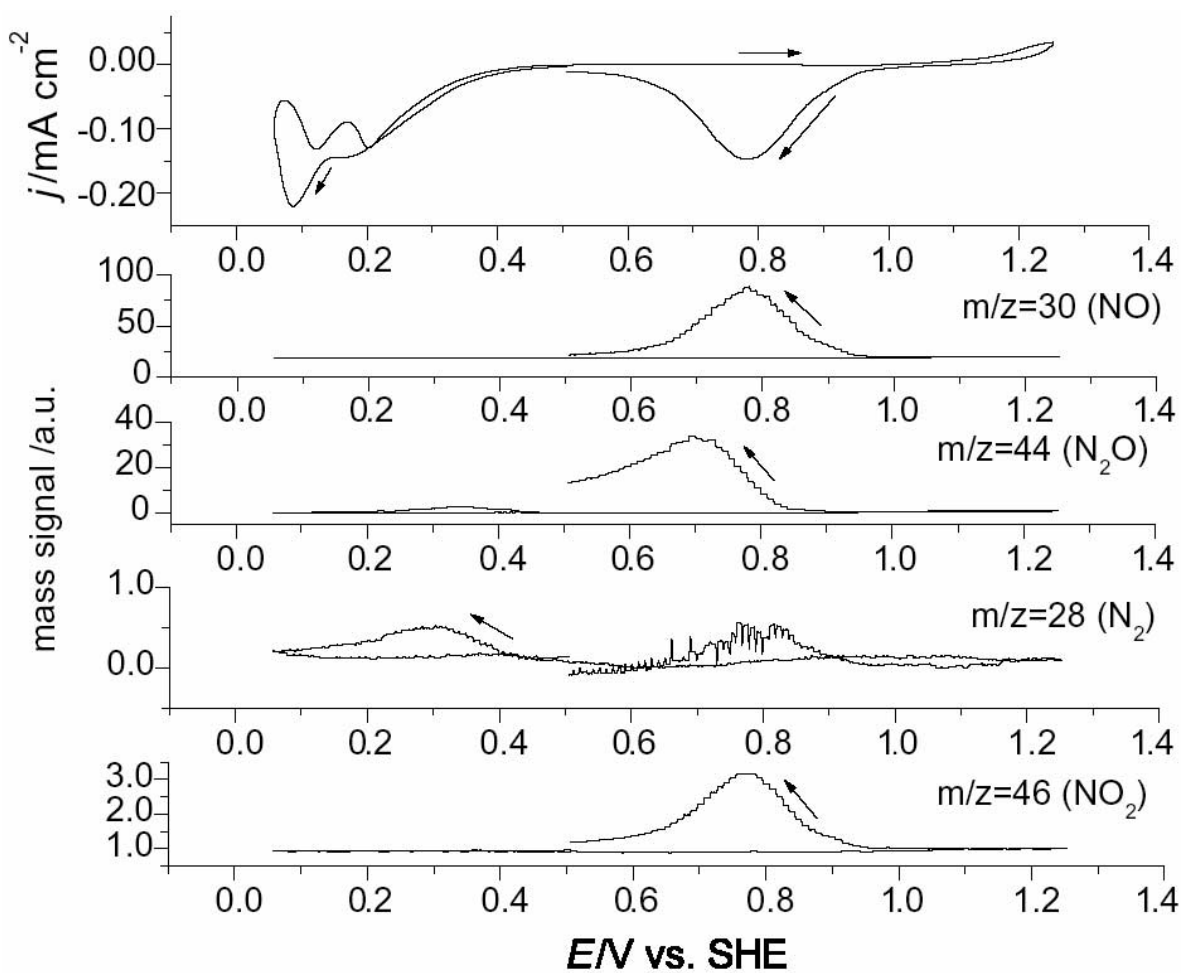

Figure 14. DEMS measurement in $4.1 \mathrm{M} H N O 3$ in $0.5 \mathrm{M} \mathrm{H} 2 \mathrm{SO} 4$. Scan rate: $10 \mathrm{mV} / \mathrm{s}$. Platinized electrode. With permission from ref. [19].

sweep in anodic direction, a peak in the ion current for $\mathrm{CO}_{2}$ around $0.7 \mathrm{~V}$ is typical for the oxidation of adsorbed CO. Since control experiments with ethylene glycol have shown, that it adsorbs at Pt under decomposition to adsorbed CO (also cf. [45]), it is clear that this peak corresponds to the $\mathrm{C}$ atoms of the crown ether ring. On the other hand, for $\mathrm{Pt}(111)$ no indication for a decomposition of this molecule at low potentials is found.

\section{Nitrogen Species}

Besides carbon, the element with the largest number of abundant volatile compounds is nitrogen. Reaction of nitrogen compounds are therefore well suited for being studied by DEMS. Among these are $\mathrm{NO}_{2}{ }^{-}[46,47]$, leading to $\mathrm{NO}_{2}$ upon oxidation and $\mathrm{N}_{2} \mathrm{O}$ upon reduction, and $\mathrm{NH}_{2} \mathrm{OH}$ [46], leading to a variety of oxidation products. The reduction of $\mathrm{NO}$ was also studied on $\mathrm{Au}$ simple crystal electrodes [48]. $\mathrm{N}_{3}{ }^{-}$is oxidized to $\mathrm{N}_{2}$, $\mathrm{NO}, \mathrm{NO}_{2}$, and to $\mathrm{N}_{2} \mathrm{O}$ on $\mathrm{Au}$ and Pt electrodes. Only on Pt electrodes it is also reduced, leading to $\mathrm{N}_{2}, \mathrm{~N}_{2} \mathrm{H}_{4}$, and possibly $\mathrm{NH}_{3}$ [49]. An illustrative example for the varity of products formed and detected during reduction of nitrate is shown in Figure 14 [19]. Note that the formation of $\mathrm{N}_{2} \mathrm{O}$ does not parallel that of $\mathrm{NO}$ and $\mathrm{NO}_{2}$ and thus is related to a different mechanism. Details of the complicated mechanisms cannot be discussed here, the reader is referred to the original paper.

\section{Conclusions}

DEMS can be used for both on-line detection of electrochemical reaction products and the study of adsorbates. Reaction- and desorption products can be determined semi-quantitatively. Since, in many cases several products are formed, it is important to know their amounts in order to distinguish between the main and side reactions.

As to the detection of electrochemical reaction products, it has the advantage over other methods, e.g., chromatography, of being fast and highly sensitive. Amounts below one nmol can be easily detected. Thus, it is ideally suited for studying reactions at single crystal electrodes with their limited overall surface area; besides, the maximum time of reaction at single crystals is limited due to their possible deterioration by contaminants. In comparison to FTIR spectroscopy, DEMS has the advantage of an easier potential control, because the thin layer is $50-100 \mu \mathrm{m}$ thick instead of only (ill-defined) $1 \mu \mathrm{m}$. The disadvantage, of course, is that only volatile products can be detected. On the other hand, species can be detected that are not IR active. Both techniques yield complementary information.

\section{Acknowledgments}

The author thanks the DFG for financial support. 


\section{References}

1. Bruckenstein, R. R.; Gadde, J. J. Am. Chem. Soc. 1971, 93, 793.

2. Wolter, O.; Heitbaum, J. Ber. Bunsenges. Phys. Chem. 1984, 88, 2-6.

3. Wolter, O.; Heitbaum, J. Ber. Bunsenges. Phys. Chem. 1984, 88, 6-10.

4. Kotiaho, T.; Lauritsen, F. R.; Choudhury, T. K.; Cooks, R. G. Anal. Chem. 1991, 63, 875A-883A.

5. Tegtmeyer, D.; Heindrichs, A.; Heitbaum, J. Ber. Bunsenges. Phys. Chem. 1989, 93, 201-206.

6. Hartung, T.; Schmiemann, U.; Kamphausen, I.; Baltruschat, H. Anal. Chem. 1991, 63, 44-48.

7. Jusys, Z.; Massong, H.; Baltruschat, H. J. Electrochem. Soc. 1999, $146,1093$.

8. Jambunathan, K.; Jayaraman, S.; Hillier, A. C. Langmuir 2004, 20, 1856-1863.

9. Jusys, Z.; Kaiser, J.; Behm, R. J. Langmuir 2003, 19, 6759-6769.

10. Jusys, Z.; Behm, R. J. J. Phys. Chem. B 2001, 105, 10874-10883.

11. Heitbaum, J.; Rach, E.; Willsau, J.; Wohlfahrt-Mehrens, M. Dechema-Monographien 1986, 102, 235-246.

12. Maschmeier, C.-P.; Baltruschat, H. Electrochim. Acta 1992, 37, 759.

13. Weber, M.; Wang, J.-T.; Wasmus, S.; Savinell, R. F. J. Electrochem. Soc. 1996, 143, L158-L160.

14. Bittins-Cattaneo, B.; Cattaneo, E.; Königshoven, P.; Vielstich, W. In Electroanalytical Chemistry, a Series of Advances; Bard, A. J., Ed.; Vol. XVII. Marcell Dekker: New York, 1991; pp 181-220.

15. Baltruschat, H. In Interfacial Electrochemistry, Wieckowski, A., Ed.; Marcel Dekker, Inc.: New York, Basel, 1999; pp 577-597.

16. Eggert, G.; Heitbaum, J. Electrochim. Acta 1986, 31, 1443-1448.

17. Maschmeier, C.-P.; Baltruschat, H. Electrochim. Acta 1992, 37, 759-761.

18. Dülberg, A. In Institut für Physikalische Chemie; Universität Witten-Herdecke: Witten-Herdecke, 1994; p 164.

19. de Groot, M. T.; Koper, M. T. M. J. Electroanal. Chem. 2004, 562, 81-94.

20. Willsau, J.; Heitbaum, J. Electrochim. Acta 1986, 31, 943-948.

21. Clavilier, J.; Albalat, R.; Gomez, R.; Orts, J. M.; Feliu, J. M.; Aldaz, A. J. Electroanal. Chem. 1992, 330, 489-497.

22. Baltruschat, H.; Schmiemann, U. Ber. Bunsenges. Phys. Chem. 1993, 97, 452-460.

23. Hartung, T.; Baltruschat, H. Langmuir 1990, 6, 953-957.

24. Schmiemann, U. In Institut für Physikalische Chemie; Universität Witten-Herdecke: Witten-Herdecke, 1993; p 120.
25. Müller, U. In Institut für Physikalische Chemie; Universität Witten-Herdecke: Witten-Herdecke, 1996; p 144.

26. Smith, S. P. E.; Casado-Rivera, E.; Abruna, H. D. J. Solid State Electrochem. 2003, 7, 582-587.

27. Bogdanoff, P.; Friebe, P.; Alonso-Vante, P. J. Electrochem. Soc. 1998, 145, 576-582.

28. Axthelm, R.; Bänsch, E.; Löffler, T.; Baltruschat, H., unpublished.

29. Gao, Y.; Tsuji, H.; Hattori, H.; Kita, H. J. Electroanal. Chem. 1994, 372, 195-200.

30. Wonders, A. H.; Housmans, T. H. M.; Rosca, V.; Koper, M. T. M., to be submitted.

31. Jambunathan, K.; Hillier, A. C. J. Electrochem. Soc. 2003, 150, E312-E320.

32. Ianniello, R.; Schmidt, V. M. Ber. Bunsenges. Phys. Chem. 1995, 99, 83-86.

33. Löffler, T. In Institut für Physikalische und Theoretische Chemie; Universität Bonn: Bonn, 1997; p 93.

34. Bagotzky, V. S.; Vassiliev, Y. B.; Khazova, O. A. J. Electroanal. Chem. 1977, 81, 229.

35. Wang, H. S.; Wingender, C.; Baltruschat, H.; Lopez, M.; Reetz, M. T. J. Electroanal. Chem. 2001, 509, 163-169.

36. Wang, H.; Löffler, T.; Baltruschat, H. J. Appl. Electrochem. 2001, 31, 759-765.

37. Jusys, Z.; Vaskelis, A. Electrochim. Acta 1997, 42, 449-454.

38. Jusys, Z. J. Electroanal. Chem. 1994, 375, 257-262.

39. Jusys, Z.; Vaskelis, A. Langmuir 1992, 8, 1230-1231.

40. Jusys, Z.; Vaskelis, A. J. Electroanal. Chem. 1992, 335, 93-104.

41. Anastasijevic, N. A.; Baltruschat, H.; Heitbaum, J. Electrochim. Acta 1993, 38, 1067-1072.

42. Löffler, T.; Baltruschat, H. J. Electroanal. Chem. 2003, 554/555, 333-344.

43. Löffler, T.; Drbalkova, E.; Janderka, P.; Königshoven, P.; Baltruschat, H. J. Electroanal. Chem. 2003, 550, 81-92.

44. Bussar, R.; Baltruschat, H., unpublished.

45. Gootzen, J. F. E.; Visscher, W.; vanVeen, J. A. R. Langmuir 1996, 12, 5076-5082.

46. Karabinas, P.; Wolter, O.; Heitbaum, J. Ber. Bunsenges. Phys. Chem. 1984, 88, 1191-1196.

47. Wasmus, S.; Vasini, E.; Krausa, M.; Mishima, H.; Vielstich, W. Electrochim. Acta 1994, 39, 23-31.

48. Suzuki, S.; Nakato, T.; Hattori, H.; Kita, H. J. Electroanal. Chem. 1995, 396, 143-150.

49. Dalmia, A.; Wasmus, S.; Savinell, R. F.; Liu, C. C. J. Electrochem. Soc. 1995, 142, 3735-3740. 